\title{
Kreativitas Guru dalam Pembelajaran Karawitan Jawa
}

\author{
Christina Dwi Hartanti \\ Mahasiswa Program S3 Manajemen Pendidikan, Universitas Negeri Semarang, Semarang, \\ Jawa Tengah, Indonesia \\ ${ }^{(*)} \bowtie$ (e-mail) christinadwihartanti23@gmail.com
}

\begin{abstract}
Abstrak
Karawitan Jawa (Javanese Gamelan Orchestra) masih diminati sebagian orang Jawa. Dari perspektif pendidikan musik, orang-orang Jawa tidak mengalami banyak kesulitan dalam bermain gamelan sebab musik tersebut sudah menjadi bagian dari tradisi mereka. Namun tidak demikian bagi mereka yang tidak terbiasa dengan musik Jawa, terutama jika dikaitkan dengan istilah-istilah Jawa itu sendiri. Penelitian ini bertujuan mendeskripsikan kata/istilah dalam gamelan Jawa tidak hanya berhenti pada makna, tetapi lebih dari itu menjadi stimulus, sedemikian rupa, sehingga pembelajar/pemain gamelan merespons stimulus tersebut menjadi perilaku musikal. Penelitian ini berada dalam ranah konseptual dengan beberapa pendekatan psikologi. Hasil penelitian menunjukan bahwa, antusiasme akan mendorong pembelajar untuk mendalami karawitan dengan lebih dalam, terutama nilai-nilai yang terkandung di dalam kesenian Jawa tersebut (behind the text) seperti nilai filosofis, sosial, kebijakan lokal, norma kemanusiaan, nilai keugaharian, nilai kerohanian, dan terutama untuk memperoleh 'roso' yang merupakan 'roh' dari estetika karawitan Jawa.
\end{abstract}

Kata kunci: karawitan, istilah, kreativitas, perilaku.

\begin{abstract}
Javanese Karawitan (Javanese Gamelan Orchestra) is still in demand by some Javanese. From the perspective of music education, Javanese people do not experience much difficulty in playing gamelan because the music has become part of their tradition. However, this is not the case for those who are not familiar with Javanese music, especially when it comes to Javanese terms themselves. This study aims to describe words/terms in Javanese gamelan not only stop at meaning, but more than that as a stimulus, in such a way that gamelan learners/players respond to the stimulus into musical behavior. This research is in the conceptual realm with several psychological approaches. The results show that enthusiasm will encourage students to explore karawitan more deeply, especially the values contained in the Javanese arts (behind the text) such as philosophical, social, local policies, human norms, religious values, spiritual values, and especially to obtain 'roso' which is the 'spirit' of Javanese musical aesthetics.
\end{abstract}

Keywords: gamelan-orchestra, terms, creativity, behavior.

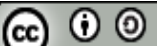

This work is licensed under a Creative Commons Attribution-ShareAlike 4.0 International License. Copyright (C) 2021 Christina Dwi Hartanti

\section{Proses Artikel}

Diterima 29-04-2021; Revisi 08-06-2021; Terbit Online 24-06-2021 


\section{Pendahuluan}

Karawitan Jawa adalah musik tradisional etnis Jawa, berupa seperangkat gamelan, yang masih berkembang di komunitas orang Jawa. Memiliki akar kata "rawit" yang berarti "halus". Karawitan juga disebut "gamelan orchestra"; memiliki dua modus utama: pelog dan slendro. Secara fungsional, awalnya seni musik ini sakral dan hanya dimainkan di dalam upacaraupacara tertentu di keraton, namun kini cenderung menjadi hiburan, walaupun beberapa gendhing masih bersifat sakral. Menurut Ranggawarsita dalam "Pustaka Raja Purwa", seperti dikutip (Yudoyono, 1984, p.24), gamelan sudah ada sejak tahun 326 Caka atau 404 Masehi, bertepatan dengan kedatangan orang Hindu Jawa. Dari perspektif mitologis, gamelan Jawa diciptakan oleh Batara Guru. Gamelan orkestra ini juga terdapat pada relief Karmawibangga di candi Borobudur. Hal itu mengindikasikan, gamelan sudah populer di masa pemerintahan Samarotungga, pendidir Borobudur, dari wangsa Syailendra (Sailendravamsa).

Memasuki Abad 20, karawitan Jawa semakin menarik perhatian musikolog dari manca negara. (Kunst, 1949) dan (Hood, 1966) adalah dua dari sekian banyak musikolog yang membahas estetika dan sejarah perkembangan gamelan di Jawa. Di era modernisasi saat ini, karawitan Jawa tetap diminati komunitas orang Jawa dan sebagian orang yang bukan etnis Jawa, terutama yang tinggal di wilayah Yogyakarta dan Jawa Tengah. Beberapa institusi pendidikan, dari tingkat sekolah dasar sampai perguruan tinggi masih menyelenggarakan kesenian ini, terutama untuk acara-acara tertentu. Di dusun-dusun tidak sedikit kelompok masyarakat yang secara rutin berlatih karawitan Jawa.

Bagi mereka yang tumbuh dan berkembang di dalam kebudayaan Jawa, mempelajari gamelan relatif tidak terlalu sulit dibandingkan mereka yang sama sekali tidak mengenal dengan baik kebudayaan Jawa, termasuk masyarakat urban, walaupun mereka sudah memahami dasar musikologi Barat. Menurut (Seeger, 1977, p.66), sebabnya adalah menteorikan musik Jawa ke dalam musik Barat sama halnya mengalihkan sistem komunikasi yang satu ke yang lain, padahal setiap kebudayaan memiliki filosofi yang berbeda-beda. Berdasarkan fakta tersebut, penulis mengkaji pentingnya pemahaman terhadap istilah-istilah di dalam karawitan Jawa dalam konteks pembelajaran kesenian karawitan Jawa, terutama bagi pembelajar yang belum mengenal kebudayaan Jawa dengan baik. Pemahaman istilah ini penting sebab sebuah istilah mengacu pada konsep tertentu. Oleh karena itu dibutuhkan kreativitas guru agar pembelajar (karawitan) awal lebih cepat dalam memahami konsepkonsep musikologis di dalam karawitan Jawa. Melalui teori psikologi kognitif, konsep-konsep yang terkandung di dalam istilah-istilah Jawa, menjadi stimulus bagi siswa agar lebih cepat dalam menguasai permainan karawitan. Tulisan ini dibatasi hanya pada analisis pemahaman istilah karawitan Jawa saja.

\section{Pembahasan}

\section{Istilah-istilah Umum Karawitan Jawa}

Sebuah istilah (terminology) bisa berupa kata atau frasa yang memiliki fungsi kebahasaan dan memiliki perbedaan makna. "Kata" adalah satuan kebahasaan terkecil, dan "frasa" menurut Harimurti Kridalaksana, seperti dikutip (Pehala, 2017), adalah gabungan dua kata atau lebih yang tidak bersifat predikatif. (Chung, 2007) mengungkapkan, secara linguistis, kata memiliki banyak fungsi; "we use words to convey our emotions and thoughts, to tell stories, and to understandthe world." Istilah-istilah karawitan tidak lepas dari fungsi itu, yakni 
sebagai sarana ungkapan emosi dan pemikiran, untuk menceritakan sesuatu, dan untuk memahami suatu dunia. Dalam konteks karawitan, "dunia" ini adalah dunia pemikiran orang Jawa. Setiap istilah Jawa memiliki reference yang berhubungan dengan pemikiran orang Jawa tentang segala sesuatu. Pada tabel 1 adalah daftar istilah yang lazim terdapat di dalam karawitan Jawa yang dirangkum dari beberapa sumber (Supanggah, 2002; Supanggah, 2009; Martopangrawit, tanpa tahun; Gitosaprodjo, 1971). Yang perlu dicatat adalah bahwa istilah ini relatif belum baku, sebab tidak jarang makna dari istilah tertentu berbeda dengan yang lain. Oleh karena itu penggunaan istilah ini sangat tergantung pada konteks.

Tabel 1. Istilah umum dalam karawitan

\begin{tabular}{ll}
\hline Istilah & Arti \\
\hline Ricikan & Perangkat \\
\hline Besutan & Glissando \\
\hline Garap & Komposisi \\
\hline Cengkok & $\begin{array}{l}\text { 1. Cara seseorang dalam menyanyikan } \\
\text { lagu tertentu }\end{array}$ \\
\hline 2. Kadang-kadang disamakan dengan \\
"garap" atau komposisi
\end{tabular}




\begin{tabular}{|c|c|}
\hline Pakem & Standar \\
\hline Cakepan & Teks/lirik \\
\hline Wilah & Bilah nada \\
\hline Pencon & $\begin{array}{l}\text { Wujud instrumen yang ditengahnya } \\
\text { terdapat benjolan: bonang, kethuk, } \\
\text { kenong, gong, kempul. }\end{array}$ \\
\hline Panji atau pandhe gendhing & $\begin{array}{l}\text { Pembuat gamelan, kadang-kadang } \\
\text { disebut "mpu" }\end{array}$ \\
\hline Cent & Frekuensi di dalam nada tertentu \\
\hline Soran & Jenis gendhing yang gagah \\
\hline Senggakan & $\begin{array}{l}\text { Model nyanyian interlocking/tanya } \\
\text { jawab }\end{array}$ \\
\hline Kyai atau Nyai & $\begin{array}{l}\text { Seperangkat gong dengan artikulasi } \\
\text { "mistis" }\end{array}$ \\
\hline Abdi dalem & Pegawai keraton \\
\hline Goro-goro & $\begin{array}{l}\text { Adegan di tengah-tengah pertunjukan } \\
\text { wayang, bersifat komedi. Tokoh yang } \\
\text { lazim muncul: Semar, Petruk, Gareng, } \\
\text { Bagong, , yang sering disebut punakawan }\end{array}$ \\
\hline
\end{tabular}

\section{Teori Psikologi Kognitif}

Psikologi kognitif adalah cabang dari psikologi, yakni ilmu yang mempelajari tentang arus informasi (bisa dalam bentuk kebahasaan) yang ditangkap oleh indera, diproses di dalam jiwa seseorang, sebelum diendapkan dalam kesadaran atau diwujudkan ke dalam pola perilaku (Goldstein, 2011, p.7). Proses pengendapan informasi di dalam jiwa seseorang disebut "mental response", yang dapat berupa "attention" (perhatian) dan "perceiption" (tanggapan). Jadi psikologi kognitif adalah bagaimana cara manusia menerima, mempersepsi, mempelajari, menalar, mengingat, dan berpikir, serta bagaimana hal tersebut terwujud di dalam perilaku. Materi yang terdapat di media audio visual membangun "mental response" setelah melalui proses "attention" dan "perception". Setelah mengalami proses tersebut munculah yang disebut behaviour response, sebuah tanggapan berupa perilaku. Perjalanan arus informasi itu dapat dilihat pada bagan 1 . 


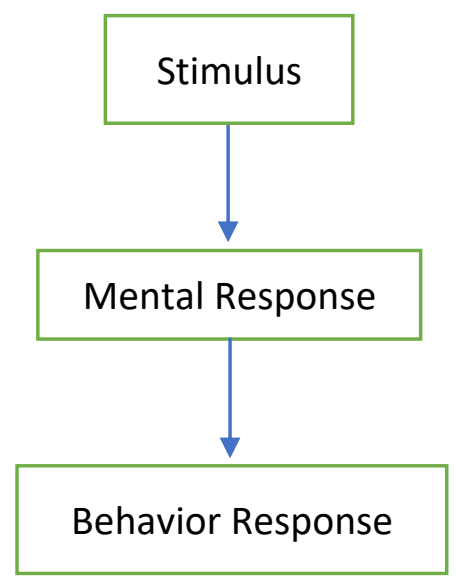

Bagan 1. Perjalanan arus informasi dalam perspektif psikologi kognitif

Pada dasarnya teori ini mirip dengan teori komunikasi (Craig, 1999, p.119-161). Perbedaaannya hanya penekannyannya. Menurut Craig, tidak ada teori komunikasi yang paling benar, akan tetapi teori-teori yang ada berguna sebagai bentuk pemikiran dalam memecahkan masalah yang lebih spesifik; "There is no one correct theory of communication but many theories are useful for thinking about specific problems." Itulah sebabnya Craig membedakan teori komunikasi ke dalam tujuh tradisi yakni (1) tradisi semiotik; (2) tradisi phenomenologis; (3) tradisi cybernetic; (4) tradisi sosiopsikologis; (5) tradisi sosiokultural; (6) tradisi kritis; dan (7) tradisi retorikal Pada dasarnya setiap tradisi ini saling berhubungan satu dengan yang lain dan digunakan berdasarkan konteks permasalahannya.

Akan tetapi di dalam tulisan ini yang dipakai adalah teori di dalam tradisi sosiopsikologis sebab lebih berhubungan dengan topik yang akan dibahas. Menurut Craig, di dalam tradisi sosio-psikologis, komunikasi merupakan ekspresi, interaksi dan memberi pengaruh terhadap orang lain (Craig, 1999, p.142). Di Abad 20 tradisi ini disebut "science of communication". Teori ini menganggap komunikasi sebagai proses ekspresi, interaksi yang memberi pengaruh kepada orang lain untuk mengungkapkan emosi dan berperilaku (Craig, 1999, p.143). Teori ini berfokus pada perilaku manusia sebagai makhluk sosial, aspek-aspek psikologis, hal-hal yang berpengaruh secara individual, kepribadian dan perasaan manusia, persepsi, dan kognisi (Littlejohn, 2011, p.52) serta berkaitan erat dengan tradisi semiotik yang menganggap komunikasi antar-manusia adalah transmisi informasi yang terjadi ketika manusia merespons adanya simbol; "Human communication has occurred when a human being responds to a symbol," (Littlejohn, 2011: 4) yang oleh filsuf Sussane K. Langer disebut sebagai "an instrument of thought" (Littlejohn, 2011, p.45).

Craig mengutip teori Charles Saunders Pierce, bahwa komunikasi semiosis terjadi karena ada hubungan antara tanda, objek, dan makna; "Peirce defined semiosis as a relationship among a sign, an object, and a meaning." Ini sangat erat hubungannya dengan konsep linguistik. Sebagai misal, kata "anjing" diasosiasikan sebagai seekor binatang. Tapi sebenarnya kata ini punya asosiasi bukan semata-mata binatang, tapi lebih dari itu, sebuah pemikiran sekaligus interpretasi atas kata itu. Bagi pecinta binatang, anjing diasosiasikan dengan binatang yang bersahabat, tetapi maknanya jadi berbeda bagi orang yang pernah digigit anjing (Littlejohn, 2011, p.45). Dalam proses komunikasi, kata-kata yang disampaikan oleh sender mengalami proses interpretasi sebelum sampai kepada receiver sebagai sesuatu yang memiliki makna. 
Hubungan dengan teori tradisi sosio-psikologis adalah makna ini membuat orang melakukan sesuatu atau mengubah perilaku. Jadi teori ini berkaitan dengan hakikat psikologi itu sendiri, yakni stimulus dan respons; "the emphasis in psychology was on how we learn behavior by associating stimulus and response." Dalam konteks pendidikan, jika sebuah respons dihargai atau diberi penguatan, dan perilaku itu diulang kembali, berkali-kali, maka itu disebut "belajar". Sebaliknya, jika sebuah respons dianggap salah dan diberi hukuman, tapi tetap dilakukan berulang-ulang, maka disebut "tidak atau belum belajar" (Littlejohn, 2011: 54). Jadi baik tidaknya komunikasi tergantung pada tingkat stimulus dan respons yang di tengah-tengahnya terjadi pengelolaan informasi. Dalam konteks tulisan ini guru memberi stimulus kepada siswa, dan siswa merespons guru. Kreativitas guru berada pada ruang pengelolaan informasi itu. Eksistensi kreativitas di dalam proses komunikatif di atas dapat dilihat pada bagan 2 .

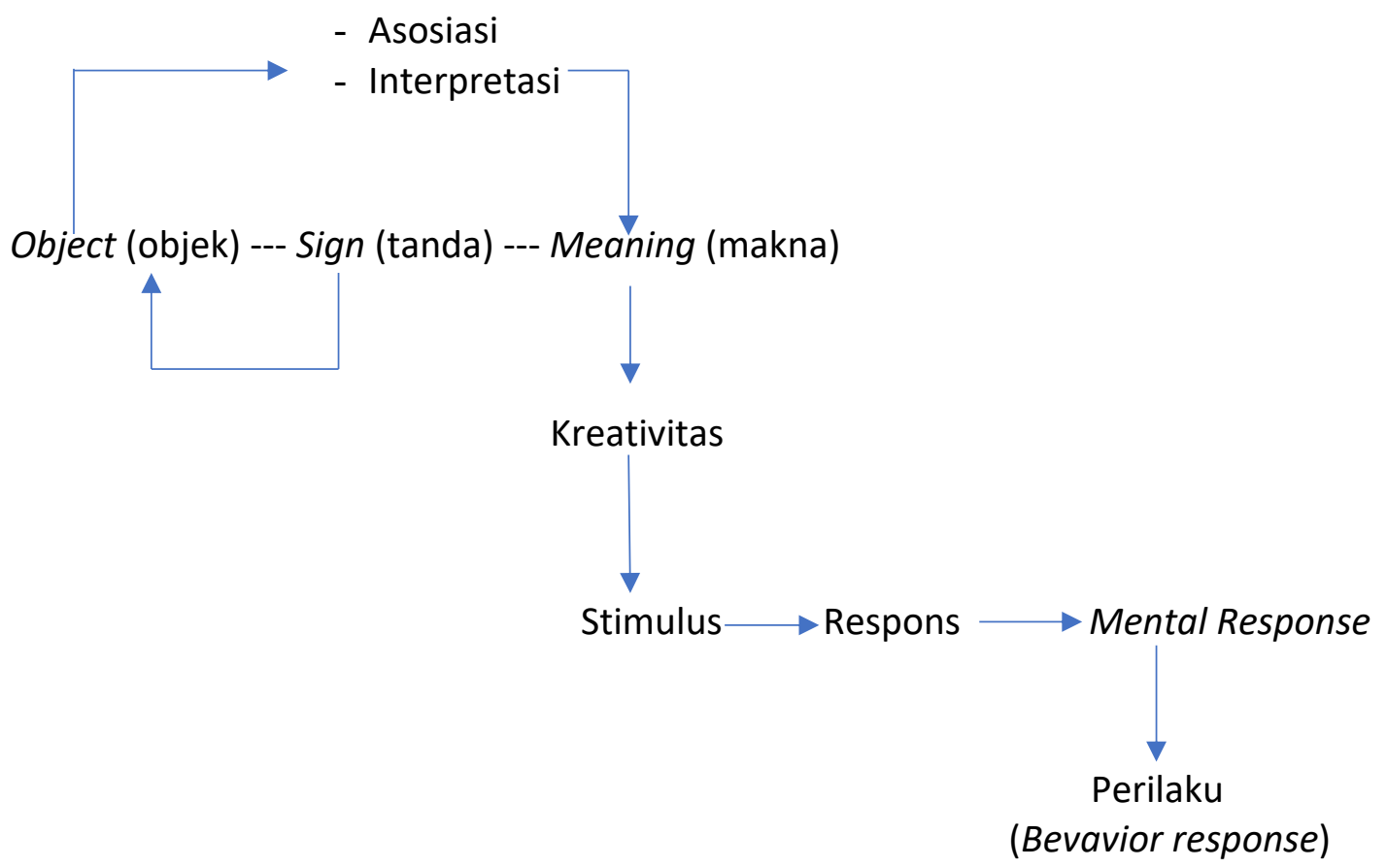

Bagan 2. Kreativitas dalam proses komunikasi

\section{Kreativitas Pembelajaran}

Istilah "kreativitas" memiliki kata dasar "kreasi" sebagai kata benda (noun), berkembang menjadi "kreatif" sebagai kata sifat (adjective). Secara etimologis berasal dari bahasa Inggris "create", yang diserap dari bahasa Latin "creatio", yang berarti "mencipta." (The Latin Classic Dictionary, Chicago, 1961). "Mencipta(kan)" berarti membuat sesuatu yang tidak ada menjadi ada, atau mengubah sedemikian rupa, sehingga yang dipandang baru diubah menjadi lebih baru. Mencipta sesuatu berarti membuat ada sesuatu yang sebelumnya belum pernah dipikirkan atau dihasilkan orang lain. (Kasmaienezhadfard, et al., 2015), dengan mengutip Torrance dan Safter, mengungkapkan bahwa kreativitas sering dianggap sebuah model yang terdapat di dalam sebuah konstruk di antara berbagai individu; "Creativity as a model that consist of some construct or dimensions between individuals." 
Di dalam kreativitas terdapat daya inovatif; sebuah konstruk baru yang belum ada sebelumnya, dan menjadi ada setelah mengalami proses pemikiran. Itulah sebabnya, munculnya daya inovasi tergantung dari kecerdasan seseorang. Inovasi pada dasarnya perubahan yang menyangkut dalam aspek tertentu dan sedikit lebih terbatas, sedangkan untuk pembaruan menyangkut lebih luas bahkan bisa terjadi secara total atau lebih menyeluruh (Iriansyah, Prosiding, tanpa tahun). Indikasinya dapat dilihat dari cara seseorang menyelesaikan masalah atau mencari jalan keluar; The indication of creative thinking in the definition that creative thinking is the ability of a person necessary to produce an alternative problem solving...." (Asrul, et.al., 2018). Di sisi lain, istilah "kreativitas" di dalam konteks tulisan ini adalah sebuah upaya baru dalam cara, bentuk dan tindakan pembelajaran karawitan. Kaplan menegaskan, bahwa teori kreativitas telah banyak membantu siswa di dalam proses pembelajaran di semua bidang pembelajaran; "Creativity theorists have advocated for teaching for creativity at all levels of education and training," (Kaplan, 2019).

Dengan demikian yang dimaksud dengan kreativitas pembelajaran adalah suatu jenis pembelajaran yang kreatif, yakni pembelajaran yang menekankan pada bagaimana guru atau tutor atau pendamping memfasilitasi kegiatan belajar, sehingga suasana belajar menjadi nyaman dan kondusif sehingga transformasi ilmu berjalan sebagaimana mestinya. Hal ini menuntut para pendidik mengemas bahan pembelajaran, sehingga pembelajar dapat terangsang dan akhirnya termotivasi untuk melakukan kegiatan kreatif dalam mencapai tujuan pembelajaran. Nyata, bahwa tuntutan kreativitas bagi guru sangatlah kompleks (Griffiths, 2014). Keadaan nyaman dan kondusif ini akan menjadi efektif jika seseorang dalam keadaan senang, seperti yang ditulis Peter Kline dalam bukunya The Everyday Genius, "learning is most effective when is's fun." (Hernowo, 2002). Jadi kreativitas bertujuan agar siswa tetap merasa senang sehingga mau tetap bertahan dalam rangka menguasai materi pembelajaran dan terus memiliki rasa ingin tau (kuriositas) terhadap materi yang didalaminya itu.

\section{Dari Istilah Menuju Perilaku}

Setiap istilah karawitan yang terdapat pada tabel di atas memiliki reference yang mengacu pada objek atau konsep tertentu. Mengacu pada tradisi semiotik Pierce bahwa sebuah kata akan memunculkan fungsi komunikatifnya jika di dalamnya terjadi kombinasi tiga hal yang bersifat tripartit yakni representasi, objek, dan interpretasi. "Tanda" adalah representasi yang paling utama; "It is a combination of representations, objects and interpretations. Its main representation is a sign," (Afisi, 2020, p.272). Proses interpretasi menghasilkan (pe)makna(an). Dengan kata lain, istilah di dalam karawitan Jawa itu adalah "tanda" sebagai representasi, yang mengacu pada objek tertentu, hingga pada akhirnya memiliki makna. Di dalam konteks pembelajaran karawitan Jawa, masalahnya adalah sulitnya pemaknaan pada tanda itu. Perbedaan pemaknaan terhadap tanda itu disebabkan oleh perbedaan kebudayaan, latar beakang dan tradisi musikal yang dengan sendirinya meminculkan perbedaan "way of thought". Permasalahannya adalah, oleh karena perbedaan-perbedaan itu, terutama para pembelajar awal, tidak memahami makna di dalam bahasa atau istilah itu sendiri. Problem kebahasaan menjadi masalah mendasar sebab bahasa merupakan bagian dari kebudayaan. Untuk mengatasi problem mendasar itu dibutuhkan kreativitas dari guru, tutor, atau pendamping.

Langkah awal yang perlu dilakukan guru adalah memperkenalkan kebudayaan Jawa itu sendiri, sebelum berbicara tentang karawitan. Guru yang kreatif akan menggunakan berbagai media pembelajaran. Media pembelajaran adalah wadah, alat, atau sarana untuk 
berkomunikasi yang dipakai selama proses pembelajaran. Ada dua unsur penting di dalam media pembelajaran, yakni perangkatnya itu sendiri dan pesan yang dibawanya. Namun demikian, penggunaan media pembelajaran diasumsikan bahwa tidak ada lagi penghalang dalam aspek penggunaan bahasa percakapan antara guru dengan pembelajar, yang disebut Silvia (2017) sebagai aspek eksternal. Pengenalan kebudayaan bisa melalui buku-buku nonfiksi tentang kebudayaan Jawa: tentang siapa orang Jawa itu? Cerita-cerita fiksi yang berkaitan dengan tradisi Jawa adalah media yang cukup baik untuk memperkenalkan budaya Jawa. Cerita-cerita dalam tradisi Jawa juga dapat diambil dari cerita-cerita pewayangan. Penyampaian cerita-cerita ini menjadi sangat penting karena nama-nama tokoh yang terdapat di dalam cerita itu bernuansa Jawa. Hal ini sangat mendukung sebab kebudayaan pada dasarnya adalah urusan nuansa. Selain itu, hal-hal yang bersifat kontekstual ini perlu dilakukan sebab, seperti dikatakan Alan P Merriam, pada daasarnya musik tradisional tidak bisa dilepaskan dari kebudayaan (Takari, 2000); karawitan Jawa adalah musik yang berada dalam bingkai kebudayaan Jawa, berbeda dengan musik Barat yang berada dalam bingkai peradaban Renaisans yang mulai berkembang di Abad 15.

Langkah selanjutnya bisa menggunakan media pembelajaran dalam bentuk audio-visual (bisa diterima indera pendengaran dan penglihatan) atau video. Strategi kreatif dalam pemanfaatan media ini akan menjadikan pembelajaran karawitan menjadi lebih efektif, interaktif, dan menarik. Penggunaan audio-visual dalam pembelajaran karawitan adalah langkah yang strategis. Gambar yang bergerak lebih cepat dalam mempengaruhi perilaku pendengarnya. Menurut Jogiyanto, seperti dikutip (Doni, 2017, p.16), perilaku adalah tindakan atau kegiatan nyata yang dilakukan karena individual mempunyai keinginan untuk melakukan sesuatu tertentu. Dalam konteks pengaruh audio-visual, perilaku itu bahkan bersifat langsung. Video tentang kebudayaan Jawa tentu lebih menarik dan lebih mempermudah audiiens-nya dalam memahami dan merasakan suasana Jawa (njawani).

Langkah yang paling strategis adalah memperkenalkan musik karawitan itu sendiri melalui media pembelajaran audio-visual. Sejauh mana daya tarik video itu, tentu sangat tergantung dari kreativitas guru. Di sinilah guru dapat langsung menjelaskan unsur penting di dalam karawitan Jawa, yakni "roso". Istilah ini secara bebas sering diartikan "menyentuh hati atau batin". Roso dapat lebih dikenali dan dirasakan berdasarkan pengalaman kultural di atas tadi. Aspek-aspek musikologis, termasuk di dalamnya ritme, harmoni, dan melodi dapat didengar dan dirasakan secara langsung.

Materi yang disampaikan melalui media pembelajaran menjadi stimulus sehingga memunculkan mental respone berupa perhatian terhadap materi tersebut. Berdasarkan teori psikologi kognitif, akan melahirkan mental behavior. Istilah "gendhing" sebagai misal, akan terdengar aneh dan asing bagi mereka yang tidak terbiasa dengan nuansa Jawa. Akan tetapi jika istilah ini telah menjadi mental response, maka mereka yang sudah mendapatkan materimateri melalui media pembelajaran tadi akan mewujudkannya di dalam perilaku. Secara konkret wujud itu bisa berupa nyanyian, senandung, bahkan permainan karawitan itu sendiri. Demikian pula dengan istilah ciblon. Istilah adalah bentuk kebahasaan yang ditangkap oleh indera, diproses di dalam jiwa seseorang, maka terjadilah mental response, sebelum diendapkan dalam kesadaran atau diwujudkan ke dalam pola perilaku (Goldstein, 2011: 7). Proses pengendapan informasi di dalam jiwa seseorang disebut "mental response", yang dapat berupa "attention" (perhatian) dan "perceiption" (tanggapan). Jadi psikologi kognitif adalah bagaimana cara manusia menerima, mempersepsi, mempelajari, menalar, mengingat, 
dan berpikir, serta bagaimana hal tersebut terwujud di dalam perilaku. Materi yang terdapat di media audio visual membangun "mental response" setelah melalui proses "attention" dan "perception". Setelah mengalami proses tersebut munculah yang disebut behaviour response, yang secara riil terwujud dengan memainkan gamelan Jawa dengan penuh antusias.

\section{Kesimpulan}

Dari hasil analisis terbukti bahwa penguasaan kebahasaan yang terwujud di dalam istilah-istilah karawitan Jawa, sangat membantu pembelajar dalam menguasai alat musik gamelan. Penguasaan istilah-istilah tersebut memang membutuhkan waktu tersendiri di dalam prosesnya. Namun demikian, kemudahan dalam mempelajari gamelan itu pada gilirannya akan meningkatkan antusiasme bagi pembelajar gamelan, terutama pembelajar pemula. Antusiasme, di sisi lain akan mendorong pembelajar untuk mendalami karawitan dengan lebih dalam, terutama nilai-nilai yang terkandung di dalam kesenian Jawa tersebut (behind the text) seperti nilai filosofis, sosial, kebijakan lokal, norma kemanusiaan, nilai keugaharian, nilai kerohanian, dan terutama untuk memperoleh 'roso' yang merupakan 'roh' dari estetika karawitan Jawa. Bagi para pengajar karawitan, sudah saatnya untuk mempertimbangkan pentingnya penguasaan aspek budaya terlebih dahulu sebelum pembelajar melakukan permainan karawitan, sebab bagaimanapun karawitan Jawa adalah bagian dari bangunan besar yang disebut "kebudayaan Jawa".

\section{Referensi}

Afisi, Oseni Taiwo. (2020). "The Concept of Semiotics in Charles Sanders Pierce's Pragmatism." Trends in Semantics and Pragmatics. Researchgate.

Asrul, et. al. (2018). "Creative Thinking Analysis, Motivation and Concept Mastery on Learning of Cooperative Discovery Model in Elementary School." Journal of Primary Education, Semarang: Universitas Negeri Semarang.

Chung, Cindy dan James Pennebaker. (2007). "The Psychological Functions of Function Word." Journal of Social Communication: Researcgate Discover the World's Research.

Craig, Robert T. (1999). "Communication Theory as a Field," Communication Theory 9.

Doni, Fahlepi Roma. (2017). "Perilaku Penggunaan Media Sosial pada Kalangan Remaja." Dalam Jurnal IJSE (Indonesian Journal of Software Engineering), 3(2).

Gitosaprodjo, Sulaiman. (1971). Ichtisar Teori Karawitan dan Teknik Menabuh Gamelan. Malang: Keluaga Karawitan Studio.

Goldstein, E. Bruce. (2011). Cognitive Psychology: Connecting Mind, Research, and Everyday Experience, United State: Wadsworts Cengage Learning.

Griffiths, Morwenna. (2014). "Encouraging Imagination and Creativity in the Teaching Profession." European Educational Research Journal: Sage Journals.

Hernowo. (2002). Belajar akan Efektif Kalau Anda dalam Keadaan "Fun". Bandung: Kaifa.

Hood, Mantle. (1966). "Slendro and Pelog Redefined." Selected Report Institut of Etnomusicology UCLA, 1(1).

Iriansyah, Herinto Sidik. (tanpa tahun). "Membangun Kreativitas Guru dengan Inovasi Pembelajaran di Masa Pandemi Covid-19." Prosiding Seminar Nasional Pendidikan STKIP Kusuma Negara II. 
Kaplan, Danielle E. (2019). "Creativity in Education: Teaching for Creativity Development." Jurnal Psychology: Scientific Research Publishing.

Kasmaienezhadfard, Sara et al. (2015). Students' Learning through Teaching Creativity: Teachers' Perception. Journal of Educational, Health and Community Psychology, 4(1).

Kunst, Jaap. (1949). Music in Java Vol. 1. Leiden: The Hague.

Littlejohn, Stephen W., dan Karen A. Foss. (2011). Theories of Human Communication. Illinois: Waveland Press, Inc.

Martopangrawit. (tanpa tahun). Pengetahuan Karawitan. Surakarta: STSI Surakarta.

Pehala, Ilvan Askul, et al. (2017). "Jenis, Fungsi, dan Makna pada Frasa dan Kata dalam Puisi Don Quixote Karya Goenawan Mohamad." Haluan Sastra Budaya, 1.

Seeger, Charles. (1977). "On the Moods of a Music Logic." Dalam Studies in Musicology 19351975. Berkeley: University California Press.

Silvia, Deny. (2017). "Teaching Media: Necessity and Important." Al-Ishlah, 9(1).

Sternberg, Robert J. (1999). “The Concept of Creativity: Prospects and Paradigm,' dalam Handbook of Creativity (Robert J. Sternberg (Ed.), Cambridge: Cambridge University Press.

Sumaryono (2013). Seni Karawitan di Yogyakarta. Yogyakarta: Dinas Kebudayaan Daerah Istimewa Yogyakarta.

Supanggah, Rahayu. (2002). Bothekan Karawitan I. Jakarta: Masyarakat Seni Pertunjukan Indonesia.

. (2009). Bothekan Karawitan II. Surakarta: ISI Surakarta Press.

Takari, Muhammad (2009). "Etnomusikologi, Ilmu-ilmu Seni dan Pengembangan Teori." Studia Kultura, No.16.

The Latin Classic Dictionary. (1999). Chicago: Follet Publishing Company.

Yudoyono, Bambang. (1984). Gamelan Jawa: Awal Mula, Maka, Masa Depannya. Jakarta: Karya Unipress. 